\title{
Breaking Boundaries: Pressing Issues in Equity, Computing, and Problem-Solving in STEM Undergraduate Education
}

\author{
Anna Bargagliotti ${ }^{1}$, Dorothea Herreiner, Jeffrey A. Phillips \\ Loyola Marymount University, USA
}

\begin{abstract}
The April 2017 National Science Foundation-funded Breaking the Boundaries in STEM Education conference brought together Southern California science, technology, engineering and mathematics (STEM) faculty to explore equity, problem-solving, and computing in an interdisciplinary manner. Two main research questions guided the overall scope of the conference: (1) What are the common threads across disciplines to approach the teaching and learning of skills that are relevant in STEM? (2) What are the challenges and barriers that need to be overcome in order to foster collaboration across disciplines to impact the teaching and learning of skills relevant in STEM? We describe the background of the conference and provide an overview of the questions addressed.
\end{abstract}

Keywords: Equity, computing, problem-Solving, STEM

\section{Introduction}

On April 7th, 2017 the National Science Foundation-funded Breaking the Boundaries in STEM Education conference (referred to as Breaking Boundaries throughout this paper) was held at Loyola Marymount University (LMU) in Los Angeles, California (NSF grant \#1644470). The conference brought together approximately 100 faculty members from the Southern California region interested in transforming classroom practice with Discipline-Based Education Research (DBER) and through the Scholarship of Teaching and Learning (SoTL), with a particular focus on equity, problem-solving, and computing - all pressing issues in STEM education. This special issue of J-STEM is dedicated to presenting results from the conference. We provide a picture of the conference and its organization as well as the themes focused on. We also discuss lessons learned and open questions. This special issue includes papers from some conference attendees related to issues that highlight particular aspects of the themes discussed at Breaking Boundaries.

An important feature of Breaking Boundaries was close attention paid to interdisciplinary collaboration. DBER is fundamentally interdisciplinary in nature as it builds on Education, Cognitive Psychology, and various STEM disciplines (SoTL is often more disciplinary, based on an instructor's own teaching). However, these connections are often within a single STEM discipline, which has resulted in the 2012 National Research Council call for more interdisciplinary studies. Rather than focusing on a topic that is only relevant to a single STEM discipline, researchers can have a greater impact by learning from each other and examining crosscutting concepts and cognitive processes. Breaking Boundaries aimed to identify similarities and differences of teaching challenges through DBER and SoTL across disciplines for each of the three themes--equity, problemsolving and computing in STEM. All sessions were attended by and had contributions from faculty in a wide variety of STEM disciplines.

${ }^{1}$ Seaver College of Science and Engineering, University Hall 2757, Loyola Marymount University, E-mail: Anna.Bargagliotti@lmu.edu

Bargagliotti, A. Herrenier, D., \& Phillips, J. A. (2018). Breaking boundaries: Pressing issues in equity, computing, and problem-solving in STEM undergraduate education. Journal of Research in STEM Education, 4(1), 2-12. 


\section{J.STEM}

Bargagliotti, Herreriner \& Phillips

Two main research questions guided the overall scope of the conference:

1. What are the common threads across disciplines to approach the teaching and learning of skills that are relevant in STEM?

2. What are the challenges and barriers that need to be overcome in order to foster collaboration across disciplines to impact the teaching and learning of skills relevant in STEM?

\section{Background: State of DBER and SoTL Research}

Discipline-Based Education Research (DBER) integrates the disciplinary knowledge and practices employed by scientists and engineers with research on human learning and cognition to address the needs of STEM education. In the Scholarship of Teaching and Learning (SoTL), instructors systematically investigate student learning and teaching strategies in their own classes in the context of the relevant pedagogical and disciplinary literature. Both, DBER and SoTL investigate instructional strategies, methods, pedagogies, and assessments in the various STEM disciplines with the goal of improving student learning. This improved learning can lead to greater recruitment and retention of students, increased diversity within STEM disciplines, and better preparation of students for STEM careers.

While DBER and SoTL have been effective at improving the learning experiences for many students, much work remains to be done. First, results of past DBER and SoTL projects have yet to be discovered by many STEM faculty so that they can influence the classroom. Adopting and adapting the research findings into widely used classroom practices occurs slowly. If progress is to be made on increasing students' participation, retention, and success in STEM, the number and diversity of institutions and faculty conducting SoTL and DBER research needs to increase.

In the past, widespread dissemination of DBER findings has been challenging. While many DBERbased curricula have been developed and shown to be effective, they are often not widely adopted or, if adopted, they are not implemented with fidelity. Dancy, Henderson, and Turpen (2016) have reported that one of the main challenges in disseminating DBER-based curricula is the desire of faculty to modify the materials. While adaptations are often driven by the desire to tailor the materials to a specific student population, teaching style, or curricular demands, faculty sometimes alter the materials in a manner or to the point of being ineffective since they are often unaware of the essential features of a teaching strategy. On the other hand, teaching strategies are generally only successful if adapted to an instructor's teaching style and well integrated into a course's context. The tension between the narrow implementation of successful teaching strategies and the adaptability to different contexts within and across disciplines is worth further investigation.

A main goal of Breaking Boundaries was to address these challenges of dissemination by having a conference structure that encouraged dialogue and focused on a geographically proximal population of researchers and instructors in order to maximize collaboration and impact (see Fuqua et al., in this special issue for discussion of the conference results). In addition, with the targeted focus on the three themes of equity, computing, and problem-solving, Breaking Boundaries sought to impact timely issues in STEM through DBER and SoTL work.

Many disciplinary conferences either focus entirely on DBER and SoTL, such as the Physics Education Research Conference (PERC) or Research in Undergraduate Mathematics Education (RUME), or include some sessions within a broader conference, such as meetings of the American Association of Physics Teachers or American Society for Engineering Education. While these conferences and sessions offer numerous opportunities for researchers and teachers to communicate, they do not include a diverse set of perspectives and typically only focus on key disciplinary approaches and questions. Researchers from different disciplines, and those within STEM, can add new ideas, experiences, and interpretations of research. Without this interdisciplinary perspective, research projects may not reach their potential or impact a larger community.

Many discipline-based DBER and SoTL research projects focus on or are limited by content 
knowledge. When groups of researchers and teachers from multiple disciplines exchange ideas they can explore commonalities and find common ground on broader issues such as equity, social factors, and skills that are employed by all STEM fields. While disciplinary conferences do sometimes focus on, for instance, affect or cultural aspects of learning (such as PERC 2013 and PERC 2014), the lack of multiple disciplines limits the possible insights and impact of the research.

Multidisciplinary SoTL conferences such as those organized by the International Society for the Scholarship of Teaching \& Learning (ISSOTL) or the Lilly Conferences on College Teaching offer the promise of multiple perspectives, however, these often do not include the STEM disciplines to a significant degree. For example, at the 2013 ISSOTL conference, approximately 5\% of the presentations were on projects based largely on a STEM discipline. While other presentations, such as those on online learning and writing across the disciplines could have been applicable to STEM researchers and teachers, they generally came from nonSTEM disciplines relying on knowledge bases and assumptions that are very different from STEM fields. A clear understanding of the relevance for STEM fields and deep roots in the respective STEM fields are essential for a long-run impact on teaching and learning. Differences in disciplinary backgrounds can open perspectives and inspire new approaches; differences that are too large can inhibit collaboration due a lack of a common language and experiences. By targeting interdisciplinary collaboration in STEM fields, we capitalize on the benefits of differences without making the differences so large that common ground is difficult or impossible to establish.

Similar to the Southern California Project Kaleidoscope (PKAL) Regional Network Annual Meetings, Breaking Boundaries aimed to improve teaching practices in STEM fields through dissemination of existing and generation of new knowledge. The Breaking Boundaries conference purposefully pushed beyond these goals by focusing on interdisciplinary inspiration and collaboration as driving and sustaining forces for the generation of new research projects. By rooting the conference in challenges experienced and approaches used by participants in their classrooms, supplemented with key presentations about methods, results, and opportunities for research and development, the conference created an environment where participants could explore options of learning from each other. The goal of the conference was to create an experience that would plant and develop the seeds for future explorations and collaborations.

\section{Background: Three Important Areas in STEM Education}

The three themes of equity, problem-solving, and computing served as the guiding framework for the conference. All three are pressing issues in STEM education that can be and have been studied through DBER and SoTL research.

\section{Equity in STEM Education}

The public and expert debate about education and also, specifically, higher education has been dominated by the concern about underrepresentation of minorities and women in STEM fields (worse in certain disciplines than others; NSF 2015) and the need for more graduates in those fields (or with those skills). Such underrepresentation has been shown to often be self-perpetuating due to the absence of role models and frequent explicit and implicit biases resulting in the so-called leaky pipeline in academia (Allen-Ramdial \& Campbell, 2014). The issue of diversity in the STEM classroom has garnered much attention due to the recent US Supreme Court discussion and subsequent statement by the President of the American Physical Society (https://www.aps.org/about/governance/letters/scotus.cfm); nevertheless, it remains an open question for some why diversity would be needed in STEM classes. In addition, the lack of diversity has also been a topic within the Black Lives Matter and other social movements. Not only is diversity generally seen as having educational value in itself (although this is controversial in several ways), enrolling, supporting, and retaining students from underrepresented groups in STEM fields is a key mandate of fairness and also efficiency.

Evidence from learning theory and psychological studies has shown that small interventions in areas such as stereotype threat (Spencer, Logel, \& Davies, 2016) or mindset (Dweck 2006) can often make a significant difference in self-image, sense of belonging, study strategies, success, and therefore retention in 
STEM fields with particular relevance for underrepresented students. Much evidence also exists that effective teaching strategies, such as active learning (Freeman et al., 2014), or regular testing (Roediger \& Karpicke, 2006) can significantly affect student learning, success, and retention. So far, there is little wider-scale evidence of successful implementation of these and other strategies that enhance student learning for STEM fields. Additionally, there is even less systematic and cross-disciplinary evidence about which teaching strategies support underrepresented students and create more equity of learning conditions. Under the theme of Equity in STEM Education, the field must open the window to implementation studies across different disciplines, courses, and institutions and facilitate a deep exploration of equity dimensions in teaching. The Equity in STEM Education sessions at Breaking Boundaries focused on better understanding of equity issues and integration of promising strategies into teaching across the STEM disciplines.

\section{Problem-Solving in STEM Education}

In the workplace, employees often are asked to solve problems in the midst of changing conditions and goals. Because of this need for independent thinking, problem-solving skills are seen as essential learning outcomes for all college graduates (AAC\&U, 2007). In the STEM disciplines, problem-solving is one of the most widely used workplace skills and listed by many professional societies as a desired student proficiency (ABET, 2014; ACS Committee on Professional Training; AIP, 2015; Zorn, 2015). In some STEM fields (such as Physics), problem-solving strategies have been heavily investigated, whereas in others (such as Economics) little work has been done, although the quantitative and qualitative nature of the course content often is similar. This allows for many opportunities to learn from each other and to further explore nuances of problems and problem-solving skills.

While employers rate problem-solving and critical thinking among the top five "very important" skills for job success, only $28 \%$ classify college graduates' problem-solving skills as excellent (Casner-Lotto \& Barrington, 2006). Another recent survey among 400 employers told a similar story, indicating that only $24 \%$ of recent college graduates were well-prepared to engage in analyzing and solving complex problems (Hart Research Associates, 2015). Other surveys similarly describe the need for improved problem-solving instruction, reporting that $64 \%$ and $82 \%$ of employers desire a greater emphasis on complex problem-solving in college (AAC\&U, 2007; Hart, 2013).

From this environment of a weaker-than-desired-problem-solving proficiency emerges the need for curricula that foster improved problem-solving skills among STEM students. To develop them, researchers will need a better understanding of the problem-solving process itself as well as tools to assess it. The ProblemSolving in STEM Education sessions at Breaking Boundaries focused on better understanding of problemsolving across the STEM disciplines.

\section{Computing in STEM Education}

The International Society for Technology in Education (ISTE) and the Computer Science Teachers Association (CSTA) define computational thinking as a problem-solving process that includes (but is not limited to) the following characteristics:

1. Formulating problems in a way that enables us to use a computer and other tools to help solve them;

2. Logically organizing and analyzing data;

3. Representing data through abstractions such as models and simulations;

4. Automating solutions through algorithmic thinking (a series of ordered steps);

5. Identifying, analyzing, and implementing possible solutions with the goal of achieving the most efficient and effective combination of steps and resources;

6. Generalizing and transferring this problem-solving process to a wide variety of problems. (CSTA \& ISTE, 2011) 
The characteristics described in this definition of computational thinking resonate with modern societal needs for STEM graduates. Wing (2006) and the National Academies Workshops on Computational Thinking reports (National Academies 2010, National Academies 2011) provide strong arguments for viewing computational thinking as essential to STEM. They describe how computational thinking allows one to choose appropriate modeling processes for a problem and use relevant aspects of a problem in order to make it tractable. Through the National Academies workshops, the collective work of over two dozen researchers in computer, information, and cognitive science supports that computational thinking skills enhance human problem-solving abilities. This occurs by extending the complexity and informational detail that can be identified when well-trained scientists employ methods of computation to solve problems involving rich and detailed data representations. The necessity for computational thinking has garnered national attention. For example, then President Obama set a goal to bring computer science to all students (https://www.whitehouse. gov/blog/2016/01/30/computer-science-all) and introduced an initiative aimed at increasing computationalthinking skills in schools (e.g., CS 10 Initiative at https://cs10kcommunity.org/).

While there has been a push to increase computational thinking, particularly for STEM students, many open questions exist about how to promote and integrate this type of thinking into the undergraduate curriculum, especially when introducing novice students to computational thinking. Of particular interest at Breaking Boundaries, was the differing degree to which computational approaches have been integrated into the curriculum of different disciplines allowing for interesting comparative approaches. The focus of this theme of the conference was to understand what role computing, coding, and general computational thinking as a problem-solving process plays in the STEM classroom across disciplines.

\section{Breaking Boundaries Conference Structure}

For each theme, a parallel schedule was created which included a contributed paper session, a working group breakout session, and a workshop for each. In addition, plenary speakers were scheduled for the entire group to start off the conference, after lunch, and at the end of the day. The following sections focus on reporting what happened in each theme throughout the day.

\section{Theme 1: Equity in STEM Education}

The conference started with Dr. Susan Singer from Rollins College giving a plenary presentation in which she described the inequities in access, persistence, and graduation in STEM education. Although there have been gains across all groups, young people with low socioeconomic status have had the smallest gains in degree attainment over the last fifty years. While more education leads to higher salaries, women need a much higher degree to make what a man with a lower education level achieves (see Carnevale and coauthors in different studies, such as the 2011 Georgetown University report). Minorities are also typically less enrolled in majors that yield high-paying jobs. Ample opportunity exists in the STEM fields and it will increase in the coming years. Although, interest in STEM fields has also been increasing, success rates are very uneven, leaving much talent out. This has consequences for economic growth and is a key question of social justice. Dr. Singer shared data that show the stark racial differences for STEM completion rates. Understanding the causes and providing appropriate support structure to address differing needs is key. According to Dr. Singer, if we want all of our students to be able to succeed, we need to address these issues.

As Dr. Singer made clear, what we can influence, and where our responsibilities lie, is the quality of our teaching as this attracts students into the STEM fields and allows them to succeed. She made reference to the 1997 study by Elaine Seymore and Nancy Hewitt, Talking about Leaving: Why Undergraduates Leave the Sciences, that showed that the overarching reason for students leaving STEM fields is poor instruction. Relying on Freeman et al's 2014 meta-study on active learning, Dr. Singer discussed the ample evidence that active learning is generally much more effective in increasing student learning and providing students with a better gauge of their understanding. Yet, we lack a robust understanding of high-quality learning environments and 
a consistent awareness of such resources and findings. Based on Bryk et al's 2015 study Learning to Improve: How America's Schools Can Get Better at Getting Better, Dr. Singer mentioned the need to change the research paradigm that supports teaching practices by bringing researchers and practitioners together. She also spoke to the need and some recent conferences that are bringing neuroscientists and STEM instructors together, so that they can jointly explore how to apply cognitive principles to courses in STEM fields at different levels. Such collaborations are essential for a better understanding of effective teaching practices as implementation details can make a significant difference in their success.

Dr. Singer mentioned the recent emergence of the student success movement that often is somewhat disconnected from the academic experience and would need to be more systematically integrated with research on classroom practices. For work in this and other areas to be successful, reliable, and meaningful metrics and a broadening of the criteria considered are needed. We have to understand how apparently teaching-unrelated aspects such as financial, cultural and emotional issues influence classroom performance and degree completion. We need to extend our analysis and the implementation to the systemic level, in particular, at the institutional level and within professional societies. (See Eubanks-Turner et al. in this special issue for a discussion about successful institutional programs that promote equity.) We need to work on all these levels, from the individual classroom to the larger disciplinary and institutional levels, from research to practice, to achieve the changes and improvements that are needed for equitable access to educational opportunities and achievements.

The Breaking Boundaries conference focused specifically on what makes an equitable classroom in the STEM disciplines and how equity can be fostered through access, diversity, learning, and content in the class. Dr. Coleen Lewis from Harvey Mudd Computer Science Department opened up the equity sessions with a twohour workshop discussing teaching tips for creating equitable classrooms. In one activity, Dr. Lewis provided participants common teaching problems and asked groups to come up with solutions. Results from that activity indicated that helpful tips for creating equity in a STEM classroom might include strategies such as: making learning goals explicit; emailing students with low grades to let them know the instructor cares and believes in them; scheduling breaks in class; embracing instructor mistakes; giving worked examples that unpack the thought process; and being explicit about teaching and student expectations. During another activity, workshop participants were given typical equity-related comments, such as: "Women are great collaborators" or "We want diversity, but don't want to water down the content." Participants noted the emotional impact of such comments and came up with responses and considered their effectiveness. Overall, the workshop provided an opportunity for faculty to think through some of their own biases and gave space for participants to suggest solutions that could be effective.

The lunchtime plenary speaker, Dr. John Brooks Slaughter, spoke about STEM education needs to bridge ideas, disciplines, and societal issues. He stated: "Those of us engaged in STEM must be today's Medici, thinking at the junction of ideas, concepts, and cultures-historically an uncomfortable place to reside."

Dr. Slaughter shared his experiences of relating STEM and equity in an ever more connected world. Alluding to the globalized society we live in, Slaughter made a plea that STEM education should focus on teaching the habits of mind of creativity, teamwork, optimism in problem-solving and design, systems thinking, and ethical considerations. These skills certainly reach across many subjects and grade levels. Slaughter's focus offered a broad approach to inclusiveness; when discussing the disciplines, he emphasized breaking down the barriers between the different silos and when discussing student learning, he emphasized the importance of being exposed to different cultures, different interests, and different points of view. In particular, he discussed bridging the humanities and the sciences. In STEM fields, we often focus too much on skills that are typical for our fields. Instead, Slaughter said: "Simply stated, our graduates should not only achieve mastery of the skills and techniques of the math, science, or engineering courses they study but they must also obtain an appreciation for accompanying human concerns and societal issues." Dr. Slaughter strongly promoted convergence (collaboration) as a way to increase access into STEM fields. 
As the contributions to the equity theme illustrated, STEM faculty want to create equitable classrooms. At the undergraduate level, it is important for faculty to understand the key role they play in making their classrooms and the learning that occurs there inclusive. This topic is often easy to ignore when focusing on learning abstract and technical concepts. Inclusivity is typically not addressed in $\mathrm{PhD}$ programs and other faculty development programs. The "burden" of achieving equitable classrooms typically is on individual faculty members who often are ill-prepared for the task. Continuous reflection on teaching practices and outcomes and the willingness to adapt teaching strategies are necessary to advance a more equitable learning experience.

\section{Theme 2: Problem Solving in STEM Education}

To start the problem-solving theme conversation, Dr. David Quarfoot (Department of Mathematics at UC San Diego) led a workshop that guided participants through the analysis of what constitutes a problem. He discussed the components that make up the problems we consider and assign in STEM fields, how different aspects of problems facilitate learning problem-solving skills, what educators value in problems, and how that differs across disciplines. By focusing on problem features, Dr. Quarfoot suggested that instructors can move from "What are the good problems?" to the more productive and specific question "What features do I want problems to have so as to further my goals?" Dr. Quarfoot defined problem features as "some dimension along which a problem may be analyzed to better understand the process of problem-solving," i.e. for him, features of problems are directly tied to the problem-solving process. He distinguished between cognitive/metacognitive and affective/belief-/society-based features, such as number of entry and exit points or cognitive engagement in the former case and such as degree of encouragement and elegance in the latter case. During the discussion among participants, it became apparent that disciplines put different weights on the problem features suggested, some being closely tied to the nature of the discipline whereas others seemed to be more tied to disciplinary convention - both offering opportunities to learn across disciplines. Dr. Quarfoot also presented results of a project in which he is measuring the presence of various problem features, the relationship between them, and the extent to which experts agree on problem features.

The presentations and discussion throughout the day built on the above understanding of problem features by looking at how students, and instructors, interact with problems (see Reinholz et al. in this special issue for a discussion of good problems across disciplines). One common topic was the role of feedback for learning problem-solving skills - the internal or metacognitive feedback by solvers themselves and external feedback provided by computer systems, coaches, and peers (see Reinholz's discussions in this Special Issue about peer review for students and future instructors). Coaches (instructors) need to provide not only feedback during the problem-solving process, but also scaffolding prior to the attempted solution. An underlying common thread of all presentations, including those on different kinds of active learning strategies related to problemsolving, was the need for careful and purposeful design, sequencing, and scaffolding of problems and problemsolving activities in a course. Not only do we need a more metacognitive approach for students to help them learn problem-solving skills, we need a more metacognitive approach for instructors designing courses and problems. This starts with choosing problems that have features that support good problem-solving practices and then includes providing structured environments in which students receive the necessary heuristics.

With participants from very different disciplines, it was interesting to see that there are many commonalities among the problems we use and, yet, there are also many differences. The problem-solving theme provided much input for a more in-depth conversation about the nature, function, and use of problems in different STEM fields. Quarfoot's list of problem features provides a framework for such a conversation; for an interdisciplinary approach, consider the role of the four dimensions suggested in the Reinholz et al paper in this Special Issue about good problems. The interdisciplinary conversation was productive and inspiring and made clear how much need there is for a continuation of the interdisciplinary conversation and hands-on development of problems. 


\section{Theme 3: Computational Thinking in STEM Education}

The morning workshop was delivered by Dr. Leo Porter from the Computer Science Department at UC San Diego. Dr. Porter's workshop touched on what it means to have "CS for all," how student misconceptions can be utilized when analyzing others' code, and how we can focus on communication in coding. Computer science is experiencing an increasing demand in most universities, so much so, that students' access to the major is restricted due to resource issues. These days, some students are entering their undergraduate work with coding experience from high school. With limited available spots in computer science majors, Dr. Porter pointed out that we need to be thoughtful about ensuring access for all, in particular, if some students are fortunate enough to come with prior knowledge and experience in coding.

In all STEM majors, some degree of coding has become required. This means that faculty in the various STEM disciplines are employing computing in many of their own classrooms. This could be simply in a pointand-click software platform, often as a means to an end (as, for instance, in many statistics packages) or it could be as complex as actually teaching some aspects of coding (see Libeskind-Hadas et al. in this special issue for presentation of different disciplinary courses that integrate computing into the course in a seamless fashion). Although STEM faculty are often sufficiently proficient coders (or users of a specific software package), in general, they do not have the depth of knowledge needed to teach students coding and computational thinking. To illustrate this shortcoming, Dr. Porter provided slightly different lines of Python code and had the participants decipher what each did. Deciphering the code proved challenging to all faculty in the room. This was because each of the lines of code targeted a particularly common misconception known in the CS education literature. This workshop highlighted the need for STEM faculty to work collaboratively with CS education faculty in order to effectively include coding and computational thinking in non-CS STEM classes.

The dinner plenary speaker, Dr. Rob Gould from the UCLA Department of Statistics, gave a thoughtprovoking presentation on data science. The premise was that in our current society we are surrounded by data and that instructors and institutions need to do more to develop a data-literate society. All citizens need the necessary skills to identify, collect, evaluate, analyze, present, and protect data. These are skills that can and should be integrated in the entire K-16 curriculum. Modern data is often comprised of a number of variable types (numerical as well as text or images, etc.), "big" data, and a complex structure with nested variables that require a database, rather than flat spreadsheet, structure. These realities of real-world data are often not reflected in curricular structures and assessments. The examples used in classroom teaching are often rather simplified applications that can easily be distilled down to a single spreadsheet rather than the more complex real-world data that students and citizens encounter in their lives. While it is difficult, it is important for our students to learn how to ask the right questions about data and draw valid conclusions from complex data.

While real data can be complex and difficult to work with, there are an increasing number of sources and tools that are available to teachers and students. Dr. Gould presented several examples of projects that are rooted in real data. One is the Mobilize Project, in which LAUSD and UCLA are collaborating to use students as sensors. Unlike "citizen science" efforts, this "participatory sensing" project is one where those collecting the data also do the analysis. In addition to collecting and analyzing the data, students and teachers engage in conversations about privacy and ownership. DataFest is an annual competition hosted by UCLA and sponsored by the American Statistical Association. In this multi-day competition, or data hackathon, undergraduate students analyze real datasets that have been provided by large corporations.

Dr. Gould pointed out that there is more work to be done. For example, researchers still have much to learn about how students perceive "data," what heuristics they use when making predictions, and the misconceptions they have when working with data. There is a need for more tools that allow students to find and analyze complex data. Most importantly, given the changes that CCSS has brought to the K12 classroom, there is a need for data literate teachers, who can also address the social issues often found within real world data. 
Overall, the computing sessions had several main ideas that consistently surfaced throughout the day. The main points that was that in order to fully integrate computing into STEM education there must be a real commitment from faculty and institutions to do so. In a sense, many STEM faculty are teaching outside their discipline when they are teaching coding and computational thinking. To approach this in a healthy way, faculty can make clear what they are trying to accomplish with code and illustrate how we would sift through code in attempting to get it to work. This process in itself would help students see the struggle. Ultimately to integrate computational thinking, however, it was proposed that team-teaching with CS education faculty would help other STEM faculty incorporate computing into their own courses. This would help STEM faculty be aware of potential student pitfalls and misconceptions. CS education faculty is greatly needed at institutions to lead efforts in integrating computational thinking through coding in STEM classes (see Schaffner \& Dekhtyar article in this special issue for discussion on garnering institutional support for computational thinking).

\section{Conclusions}

In all of the theme sessions it was apparent that for STEM education to improve, it will take an interdisciplinary, if not transdisciplinary approach. Most faculty are not sufficiently trained to address the complex issues of equity, problem-solving, and computational thinking in the STEM classroom; much has entered the different disciplines in a piecemeal and almost ad-hoc fashion and is overdue for a more systematic exploration within and across disciplines. Equity and inclusivity are generally not components of a graduate student's education. STEM faculty are experts in their disciplinary content and methods, but rarely in the sociology of their scientific community. Similarly, while STEM faculty are generally very good problem-solvers or coders, they have not been educated in how to unpack these large skill sets for students as much of their own learning happened by doing and in an unstructured fashion. Studying the role of metacognition in problemsolving or common misconceptions in computational thinking is key for aiding students, in particular, those that come equipped with fewer skills, support, or confidence but no less ability. By having conversations across the disciplines, especially the social sciences, STEM faculty may be able to make advances in research on equity, problem-solving and computational thinking. Such progress can help to increase the number and diversity of students in STEM pathways and improve students' skill sets that can be utilized in all STEM disciplines and careers.

Such conversations between individuals in different fields have to be slow and in-depth as there are many challenges to productive interdisciplinary or transdisciplinary collaborations. At the conference, we barely managed to touch upon issues and be inspired to ask more questions and follow up. While the atmosphere for the day provided ample opportunity for participation, it still was challenging to promote interaction of faculty beyond the day of the conference. Our finding was that the workshops and the working groups were perhaps the most important in stimulating conversation, while the paper sessions offered a good way to present a variety of ideas. Because of the variety, however, it was challenging to solidify emerging themes. In addition, the teaching, research, and administrative realities on the ground make such conversations difficult, if not impossible, to sustain beyond the Breaking Boundaries conference, unless there are solid institutional structures that provide time, support, and recognition within and beyond institution. We encourage those embarking on DBER and SoTL work to foster their interdisciplinary connections both within and outside their own institution (see Fuqua's discussion in this Special Issue on how to achieve this).

The questions raised and the opportunities that emerged did provide an incentive to pursue the emerging collaborations further. Having excellent speakers and a program that provided a variety of opportunities for people to engage and interact was essential for the success of the conference. To push the three themes and STEM faculty engagement in them will require conferences like Breaking Boundaries, where instructors from different fields and with different backgrounds get together and are intrigued and inspired by what they hear from others, but it will also take hands-on workshops where participants can engage in more in-depth conversations and the comparison, learning, and development of new pedagogical approaches. 
In the meantime, we rely on faculty who are "change agents" to be catalysts for DBER and SoTL collaborations and to analyze and disseminate new results about effective teaching strategies. We also rely on conferences such as Breaking Boundaries, to bring faculty together and expose them to key ideas and kindle the flame of interest in such questions. Having a truly interdisciplinary organizing team of individuals familiar with research-based instructional strategies is an important consideration when planning conferences of this type. The emergence of the DBER Alliance, https://www.aau.edu/sites/default/files/STEM\%20Initiative\%20Images/ STEM\%20PDFS/17-043\%20AAAS\%20STEMDBERAllianceflyer_rnd3.pdf, an interdisciplinary group focused on promoting DBER work across the disciplines, for example, can provide a platform for further work in this area. From a regional perspective, a conference like Breaking Boundaries offered an effective way to identify nearby people who are interested in similar work. Such a conference connects faculty across the disciplines who would not regularly communicate as they tend to do within their own disciplinary silos.

\section{References}

AAC \& U. (2007). College learning for the new global century, Washington, DC: The Association of American Colleges and Universities.

ABET Engineering Accreditation Commission. (2014). Criteria for accrediting engineering programs. Baltimore, MD: ABET.

American Institute of Physics (AIP) (2015). Focus on: Physics bachelor's initial employment. Retrieved from $<$ https://www.aip.org/statistics/undergraduate>

Allen-Ramdial, S.A., Campbell, A.G. (2014). Reimagining the pipeline: Advancing STEM diversity, persistence, and success. BioScience, 64(7), 612-618.

Casner-Lotto, J, Barrington, L. (2006). Are they really ready to work? Employers' perspectives on the basic knowledge and applied skills of new entrants to the 21st century U.S. workforce. Washington, DC: Conference Board: Partnership for 21st Century Skills: Corporate Voices for Working Families: Society for Human Resource Management.

Carnevale, A. P., Rose, S.J., Cheah, B. (2011). The college payoff: Education, occupations, lifetime earnings. The Georgetown University Center on Education and the Workforce.

Dancy, M., Henderson, C., \& Turpen, C. (2016). How faculty learn about and implement research-based instructional strategies: The case of peer instruction. Physical Review Special Topics-Physics Education Research. 12, 010110.

Dweck, C. (2006). Mindset: The new psychology of success. New York: Ballantine Books.

Freeman, S., Eddy, S. L., McDonough, M., Smith, M. K., Okoroafor, N., Jordt, H., Wenderoth, M. P. (2014). Active learning increases student performance in science, engineering, and mathematics. PNAS, 111/23, 8410-8415.

Bryk, A. S., Gomez, L. M., Grunow, A., \& Mahieu, P. G. (2015). Learning to improve: How America's schools can get better at getting better, Cambridge, MA: Harvard Education Press.

Hart, R. (2013). It takes more than a major: employer priorities for college learning and student success. Washington, DC: The Association of American Colleges and Universities.

Hart Research Associates. (2015). Falling short? College learning and career success. Washington, DC: The Association of American Colleges and Universities.

National Academies. (2010). Computational thinking for everyone: A workshop series Workshop 2 February 4, 2010 - February 5, 2010, The National Academies, workshop participant Report of a Workshop of Pedagogical Aspects of Computational Thinking, The National Academies Press, 2011 http://www.nap. edu/catalog.php?record_id $=13170$

National Academies (2011). Computational thinking for everyone: A workshop series Workshop 1 February 19, 2009 - February 20, 2009, The National Academies, workshop participant and report reviewer. Report 
on the Scope and Nature of Computational Thinking, The National Academies Press, $2010 \mathrm{http}: / /$ www.nap. edu/catalog.php?record_id $=12840$

National Research Council. (2012). Discipline-Based education research: Understanding and improving learning in undergraduate science and engineering. Washington, DC: The National Academies Press.

Roediger, H. L., \& Karpicke, J. D. (2006). Test-enhanced learning: Taking memory tests improves long-term retention. Psychological Science, 17, 249-255

Spencer, S. J., Logel, C., Davies, P. G. (2016). Stereotype threat. Annual Review of Psychology, 67, 415-437.

Wing, J. (2006). Computational thinking. Communications of the ACM, 49(3).

Zorn, P. (2015). 2015 CUPM Curriculum guide to majors in the mathematical sciences. Washington, DC: Mathematical Association of America. 